\title{
Reworking the archive: Experimental arts, memory and imagination
}

\author{
Katherine Moline and Jacqueline Clayton
}

\begin{abstract}
Over the past 50 years institutional critique has become a part of the contemporary programming of museum exhibitions produced by practitioners in design, craft and visual art. Challenges and critiques of orthodoxies in museology have developed in response to changing social practices. This paper considers two site-specific installations, I cling to virtue (2010) by Onkar Kular, Noam Toran and Keith R. Jones at the Victoria and Albert Museum, London, and Pleased to meet you: introductions by Gwynn Hanssen Pigott (2012-2013) at the Museum of Anthropology, The University of British Columbia, Vancouver. Both works invited visitors to engage with the artists' invented arrangements and to attend to subjective responses as authoritative readings of museum display. In other words, they questioned institutionally directed interpretation and brought key aspects of globalisation into view. This paper first describes the installations, then places them within the framework of globalisation and the social imaginary proposed by Arjun Appadurai and Cornelius Castoriades. It discusses concepts of the heterogeneity of globalisation within the framework of the social imaginary evoked in the installations and analyses the works in these terms. The replaying of historical material in these works, we contend, questions the negative implications of globalisation. Further, the definition of interdisciplinarity framed by the social imaginary provides fertile ground for reconceptualising specialisation. When seen within the social imaginary, the experimental approach to curatorial and exhibition norms exemplified by the two installations provides intriguing models for intervening in the archives and histories of design, craft and visual art.
\end{abstract}

\section{Introduction}

Creative interventions enacted in museums by designers, crafts practitioners and visual artists are an increasingly visible element in the exhibition schedule of public institutions. As an art historical tradition, these interventions have focused institutional critique and questioned norms and conventions of art exhibition. Institutional critiques that we see as pertinent to the works we will discuss shortly include: a museum invented in a Brussels home, Musée d'Art Moderne, Département des Aigles, by Marcel Broodthaers (1968); the arrangement of artefacts retrieved from a museum storeroom in Andy Warhol's Raid the ice box (1970); Hans Haacke's Shapolsky et al. Manhattan real estate holdings, a real time social system, as of May 1, 1971 (1971), which traced the ownership of New York tenement buildings and the social relationships thus defined; the interrogation of racism in museological practices in installations such as Mining the museum by Fred Wilson (1992); Andrea Fraser's Little Frank and his carp 
(2001), shot at the Museo Guggenheim Bilbao - an eroticised response to the architectural spectacle of contemporary museums and the Schildbach Xylotheque 'Wood Library' by Mark Dion for Documenta 13 (2012). Over the last two and a half decades, museums have taken the critique of their practices as a force within the institution. The exhibitions we discuss in this paper were, for example, developed by the invitation of the respective museums in which they were installed.

In a comparison of two recent museum-based interventions affiliated with design and craft, we consider how such installations evoke tensions between history and memory, institutions and individuals. I cling to virtue by British designer Onkar Kular, American-born English artist Noam Toran and US poet Keith R. Jones (2010) and Australian ceramicist Gwyn Hanssen Pigott's interpretive arrangements of objects exhibited as Pleased to meet you: introductions by Gwyn Hanssen Pigott (PTMY) (2012-2013), each foreground the past and the present in suggestive ways. These are not the first reflexive projects that interrogate the relationships between museum, archive and artefact in craft or experimental design discourse (Rock \& Sellers 1998; Guixé 2007; Perry 2011). We contend that the two interventions discussed in this paper differ from these critiques in their engagement with contemporary issues of migration and heterogeneity. When seen within a framework of globalisation informed by Arjun Appadurai and the concept of the social imaginary proposed by Cornelius Castoriades, the installations open up some ways in which practitioners provoke insights. We propose that these examples of creative practice exemplify the distinction Appadurai makes between the production knowledge and the consumption knowledge of objects, which is his analysis of careers of artefacts and insistence on context as the critical factor in their interpretation. If seen within the social imaginary, where institutional practices are said to reflect the fantasies of society, the experimental approach to curatorial and exhibition norms in the two installations is revealing.

\section{I cling to virtue}

The installation / cling to virtue (ICTV) presented the personal effects, photographs and video montages of Monarch Lövy Singh, a fictional character, half Ashkenazi Jewish and half Punjabi Sikh. Developed as a collaborative project by Toran, Kular and Jones, the title of the work invoking the family motto of the American Kennedy family. As a site-specific installation in the Jones Gallery of the Victoria and Albert Museum (V\&A), the work resembled the miscellany of private residue. 26 ceramic rapid prototypes of everyday things presented odd conjunctions of anomalous objects in museum vitrines. The objects were accompanied by a booklet (2010), a photographic catalogue published the following year (2011), and a statement of practice by the artists (2013). The layers of ICTV mirrored the structure of memory: fragmented, delayed and partial. 
Monarch's family legacy was framed retrospectively in 2013 as a composite of the memories of all who viewed the exhibition. As we will shortly discuss, Hanssen Pigott's curatorial narrative is understood, also, to subsume the experience of her audience. Similarly, both exhibitions entered the discourse on fact and fiction and the assumptions by which objects are read into the authoritative narratives of history. ICTV questioned the authenticity of history via the evidence of Monarch's family treasure trove. Relics such as a Bar Mitzvah cake, a Sikh comb, and a McDonald's burger container prompted curiosity about the family's travels and heritage. The combination of items seemed to present the effects of globalisation and defined their heir as a global citizen. Some objects were arranged in pairs, such as a toffee hammer and a forcefeeding tube, a model freight ship and a commemorative Olympic torch.

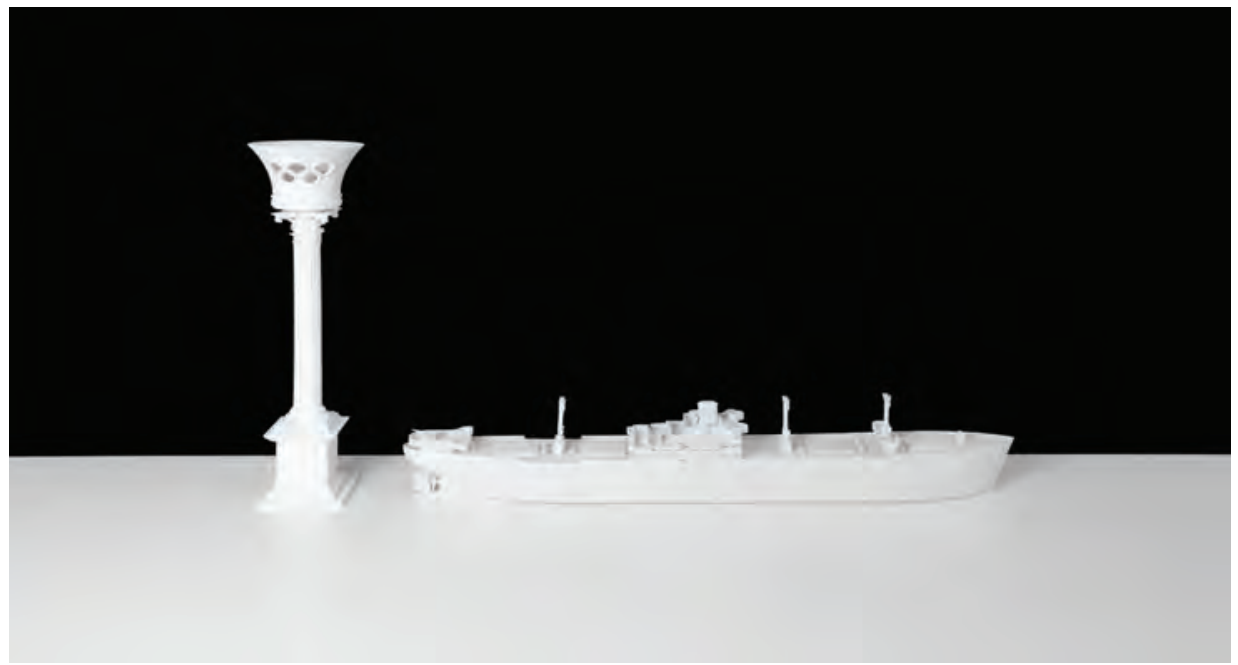

Figure 1. Onkar Kular, Noam Toran and Keith Jones, Olympics, 2010

Photo: Diego Trujillo

The installation's ambiguous display provoked questions about the conventions of design. Such experimental practices have a long-running history in design discourse. They have been variously described as 'counterdesign' (Ambasz 1972: 223), 'critical' (Dunne 1999: 12), 'postmodern' (Poynor 2003: 11), 'strangely familiar' (Blauvelt 2003: 14), 'design fiction' (Bleeker 2009: 6), 'design factions' (Auger 2013: 9) and 'speculative' (Dunne \& Raby 2013: 4). Unlike design-art that features limited edition designs by artists (Coles 2005, Williams 2009), experimental design keeps the disjuncture and gaps between disciplinary fields in play. We use the term experimental design here because it includes a range of approaches to design critique through practice. We consider experimental design as bordering contemporary art and significant for the density of its reflections on the fluidity of historical design discourse and the shaping of design futures (Moline 2007, 2012). 
Two recent descriptors qualify aspects of experimental design that are shared with other emergent practices in visual culture. Technologist and artist Julian Bleeker (2009) contends that design fiction explores how design objects embody narratives about issues surrounding technology. Echoing accounts of critical design by Anthony Dunne (1999), Bleeker also foregrounds the issue that troubles design traditionalists: its characteristic quality as 'both real and fake' (2009: 8). Designer James Auger concurs. He suggests that 'design factions' describe the difference it makes to the reception of projects if they can 'pass as real' and audiences can suspend their disbelief (Auger 2013: 9-10). Shortly, we will discuss how the differences between fake and real are pertinent to ICTV.

ICTV presented a child's tricycle in a glass vitrine at the centre of a circular room around which Monarch's family ephemera was displayed in glass-fronted cabinets. In places, a video monitor occupied a cabinet shelf. The monitors presented two video sequences. In Corridor the camera slid up the hallway of a hospital ward at the end of which a woman's face flashed on-screen as the camera turned the corner to confront an identical hallway and a repetition of the sequence. It was as if an elderly patient stalked the ward and remembered the face of a friend at the end of each lap. The second video, End credits, showed video portraits of 14 people who turned to the camera in the style of film credits of a bygone era. Some smiled. Others gazed into the distance. The acknowledgements for the video named members of the Kular and Toran families and hinted they were the actors depicted.

The booklet accompanying the exhibition opened with Kular, Toran and Jones's reflections on memory and fiction. The artists' refusal to reduce memory to a simple narrative is reflected in the description on the cover (2010) that presents the 'memoirist' as a 'fiction-maker' and memory as a 'fiction-machine'. At the same time, the booklet framed how the objects were to be interpreted: as the family's possessions that 'crisscrossed' and were 'penetrated by a larger world, more its possession than ours' (cover). The booklet's account of the fallibility of memory, perhaps as a stand-in for history, was thereby positioned in the global context. The artists' doubt about the reliability of history and memory implicitly asked museum visitors to question what they saw before them.

The timeline featured on the inside covers of the booklet presented a series of clues for the unravelling of the family narrative of migration between 1906 and 2001. Like a whodunnit, it commenced with the birth of Monarch's greatgrandfathers in India and Lithuania. The chronology allowed the viewer to construct a family tree of four generations leading to the birth of Monarch in 1972. Family anecdotes were interspersed with dates for political events, such as the foundation of the British Union of Fascists in 1932. Each page in the booklet described an item on display - it was up to the viewer to connect the dots. No matter how mundane the objects appeared at first glance, they were contextualised by constructed narratives and political events presented in the booklet (Kular et al. 2010). 


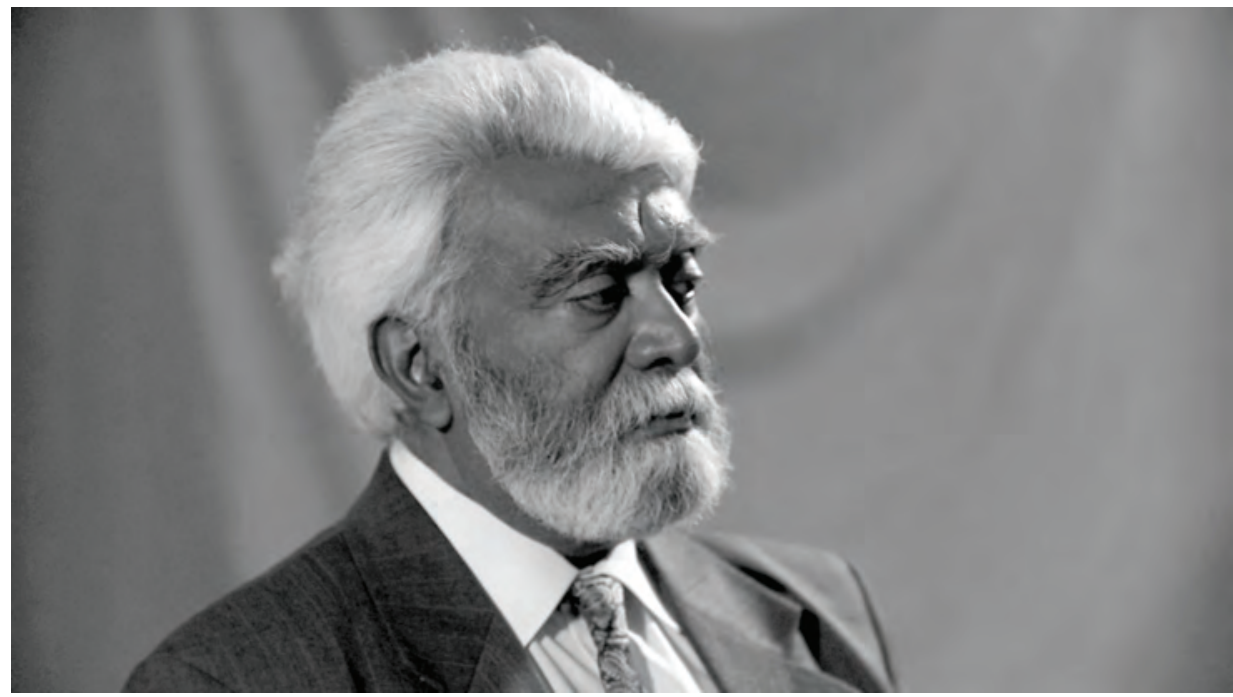

Figure 2. Onkar Kular, Noam Toran and Keith Jones, End credits, 2010

Photo: Courtesy of the artists

Connections between snippets of family gossip were developed through the cross-referencing of object, caption and timeline. Some captions were ambiguous, as they told interlinked family memories of events in the manner of a shaggy dog story. The display of the toffee hammer and force-feeding tube was described, for example, as the representation of the conflict between a mother and her daughter. According to the caption for another item, a pair of women's gloves, a failed attempt to swim the English Channel led to a romantic rendezvous. Apparently, Monarch's grandparents met when his grandfather Zalman rescued his grandmother Judith by taking her hand and running from journalists as she came ashore. He visited her the next day with a gift of gloves to warm her cold hands.

Doubt was introduced when Zalman was said to be a 'notoriously unreliable narrator' (2010: 18) who connected each of his improbable tales to a pair of women's gloves. The family mythology of chance meetings, strife and illconsidered liaisons brought together several allegories that alluded to the inconsistency of memory and any story that creates a sense of closure or totality, even those told in museums. The distortions of history, central to the ICTV experiment, were amplified in a statement of practice by the artists in combination with a review of the work published three years after the exhibition (Hayward et al. 2013). Here they referred to their practice as experimental. They claimed that 'part of that experiment lies in creating, or construing a built world' (2013: 98) and providing a 'counter-memory' (2013: 99) within the museological context. As a belated preface, the review suggested that the work subscribed to Roland Barthes's (1977) thesis of the death of the author and the birth of the 
reader. Indeed, discovering the work via this retrospective preface created the sensation of travelling backwards through time to remember an exhibition of someone else's bricolage.

The whodunnit flavour of omissions and false clues scattered throughout ICTV evoked another work, which is also concerned with artifice and artefact, by Toran, Kular and Jones - the MacGuffin Library (2008). This series of rapid prototypes, as an exploration of connections between fact and fiction, and fake and real, connected design practice and film history. The title refers to the MacGuffin, a narrative device exploited by Hitchcock to divert audiences to attend to one storyline until the twist in the narrative direction at the conclusion of the film. In short, a red herring: a falsity presented as fact. ICTV expanded this idea beyond film and fantasy into family and historical archives. Through the linking device of Monarch, ICTV extended the artists' exploration of imaginary worlds, fact and fiction, as an experimental design. Constructed in a winding narrative it was, at times, opaque. We propose that this sequential work, in progress since 2010, is illuminated by ideas of the social imaginary by Castoriades and Appadurai. Within the concept of the social imaginary, where institutions are understood to mirror the fantasies of society, we interpret ICTV as engaged with a complex of ideas that connected ephemerality, the obscurity of history, globalisation and the institutions that reflect society. We will expand on this analysis shortly.

\section{Pleased to meet you: introductions by Gwyn Hanssen Pigott}

Hanssen Pigott achieved international recognition for her simple, vessel forms: porcelain bottles and beakers exhibited as groupings or ensembles that reference the still life paintings of Italian artist Giorgio Morandi. For Hanssen Pigott, Morandi's paintings of domestic vessels exemplified a metaphoric capacity for simple objects to conjure the human setting of which they had been part. The most conventional and everyday objects, Hanssen Pigott contends, 'evoke so much that is inexpressible in any other language, about humanness' (2004: 25). It is this observation that informed the projects which she subsequently enacted in museum settings and are the subject of this discussion.

In 2007, Hanssen Pigott curated the installation Parades for the Freer Gallery of Art, Smithsonian Institution, Washington. From the museum archive of East Asian ceramics accumulated by the nineteenth-century industrialist Charles Lang Freer, Hanssen Pigott selected 72 ceramic objects that were assembled to produce seven tableaux. In constructing the groupings, the artist paid little attention to established museological systems built on didactic intent and correspondences of geography, function, material or technology. Instead, according to the Freer Curator for Ceramics, Louise Cort (2013), Hanssen Pigott chose objects that combined to educe the narrative that triggered their selection.

In staging the work, each tableau was installed and titled to suggest the referent around which it had been composed. The work Remembrance, for example, 
comprised nine ceramic vessels glazed in subdued colours of taupe, brown and blue, devoid of all but minimal surface embellishments. All were austerely vertical in their configuration: some had lids preventing a view into their interior space. The grouping, which grew to include a tray for wine cups and several Sung bowls, emerged from Hanssen Pigott's initial fascination with a dark green-glazed Han dynasty covered jar used for tomb burial. Discussion of the object between Hanssen Piggot and Cort focused on the entwinement of personal and political events in which they 'started talking about death, the Vietnam war, etc'. From that conversation, according to Cort, the 'dark work took form' (2013). The role of individual and community memory in the construction of historical knowledge is central to understanding both the methodology and modes of reading Hanssen Pigott's project. Debates on memory and history are various (Adamson 2013, Augé et al. 2004) and will be considered shortly in relation to interpretations of the social imaginary. Most pertinent to this discussion is the argument for the persistence of the past in the present, via individual and collective memory and the constitutive effects of each (Nora 1989, Clayton 2010).

Following the Freer installation, Hanssen Pigott was invited to enact a similar project, PTMY, at the Museum of Anthropology (MOA), University of British Columbia, Vancouver, exhibited November 2012 - March 2013. Again, a museum's entire inventory, in this case 38,000 artefacts sourced worldwide and representing centuries of applied human technology, was made available in order that the artist would 'invent' (MOA 2013) arrangements to contribute to the elucidatory function of the institution. Ignoring key indices of conventional museology, such as country of origin, date of production, material and provenance, Hanssen Pigott drew together 120 disparate objects that included swatches of tapa cloth, a string of glass beads, finely woven baskets and small lacquer bowls. The objects were arranged into 18 groupings, some included her own ceramic pieces. Each collection was shown in an imposing, freestanding, glass case typical of orthodox museum exhibitions.

Hanssen Pigott explained her selections at the MOA in language that distanced her from the didactic rationale often associated with the museum. Her process, as she described it, employed spontaneous and instinctual appraisals that conjured formal and poetic associations between objects: 'I usually would start with an object that enthralled or intrigued ... and then l'd search around for companions that suggested themselves to me, perhaps as a foil, or a folly, or family ...' (Conner 2012: n.p.). PTMY, as the name implies, 'introduced' and juxtaposed objects of dissimilar typology. That is, artefacts that were unlikely to be exhibited together in the conventional archival exhibition. Cort speaks of Hanssen Pigott's installation as an egalitarian series of introductions that drew into public view objects hitherto 'overlooked', 'ignored' and that 'had rarely if ever been on exhibit' due to their state of repair or the hierarchies of historical and cultural value ascribed by the norms of the institution (2013). In exercising her curatorial sensibility, Hanssen Pigott dislocated objects from their assumed value, breaching orthodox museological approaches to object selection and exhibition development. Hanssen Pigott's 
invented narratives brought together the unfashionable, the comely and plain and, in so doing, raised questions about the authority of the museum and the locus, construction and communication of knowledge.

The artefacts selected by Hanssen Pigott occupied all quadrants of the display case. Like elements of a diorama, they were arranged according to their role in a vignette conjured by the artist. In some instances, objects were attached to the upper frame of the case, suspended over or dropping into the setting of which they were part. In one cabinet a translucent, white garment hovered over two small, Han dynasty figures, the remnant detail of their white clay exterior brought into focus by the fabric above. The finesse of their surface and elongation of form was underscored by their proximity to a flat, chunky, lidded container and two squat, skin vessels.

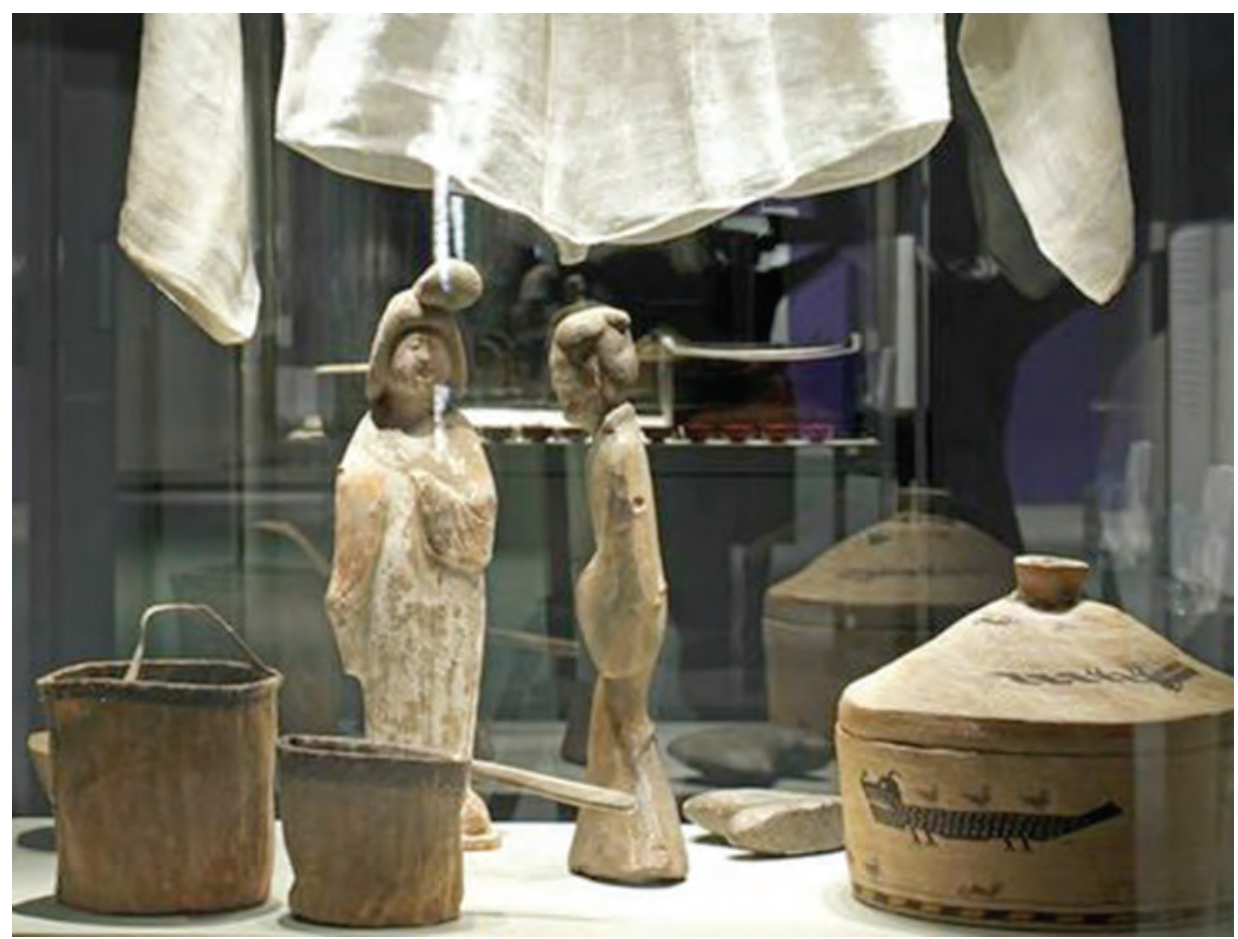

Figure 3. Gwyn Hanssen Pigott, Pleased to meet you: introductions by Gwyn Hanssen Pigott, 2012, installation shot

Photo: Ken Mayer, courtesy of the UBC Museum of Anthropology

In another cabinet, several small bamboo whisks were placed opposite a large, palm leaf fan that extended horizontally toward two unfinished baskets with unwoven canes spiralling into the space of the cabinet. In language consistent with the sensibility around which the installation had been curated, arts critic Robin Laurence described this grouping in terms that underscored an aesthetic and sensory response, where 'impact' is 'created' through 'the impossible 
lightness of their being and the delicate network of shadows they cast' (2012). In the installation at MOA, as at the Freer Gallery, descriptive case labels were minimised. Explanatory texts were 'purposefully positioned away from the cases, so that visitors would confront the groupings ... for what they were visually and viscerally' (Cort, personal communication,19 June 2013).



Figure 4. Gwyn Hanssen Pigott, Pleased to meet you: introductions by Gwyn Hanssen Pigott, 2012, installation shot

Photo: Ken Mayer, courtesy of the UBC Museum of Anthropology

The MOA's employment of an artist to demonstrate imaginative play (in essence to model the fantasies that are possible when confronted with a collection of historical artworks and artefacts) prompts questions about institutional authority and expert knowledge. 


\section{Appadurai's and Castoriades's concept of the social imaginary}

In short, Castoriades's theory of the social imaginary questions the usual categorisations of social strata and contends that institutions are manifestations of the beliefs and fantasies of the individuals who comprise society (1997: 71). Within this framework, museums can be seen as the institution of history, a shared construction that is formed by collective beliefs about a society's structures and experiences of the past, and a funnel that directs and perpetuates these views.

In his elaboration of the theory, Appadurai grants substantial agency to the subject and argues that globalisation produces heterogeneity, rather than the homogeneity with which it is often associated (see, for example, Woodham 1997). He contends that when new images and ideologies are 'indigenised' (Appadurai 1996: 32), that is, appropriated and modified to fit local customs in new contexts, they produce difference. In understanding the effects of globalisation, 'context is everything' (1996: 76). Appadurai's emphasis on context is one explanation for why societies respond differently to institutional configurations. He insists that 'what we need to avoid is the search for pre-established sequences of institutional change' (1996: 73). From our perspective, when the expectation of repetitions of the habitual is acknowledged, difference becomes evident.

Just as context is critical to Appadurai, so too is the site of encounter. He speaks of 'poles' in 'careers' or 'life histories' of objects (1999: 41) and, in so doing, draws attention to the movement of objects from the point (or pole) of production to the point of consumption and the consequent disjunction in knowledge. As they transition between these points, objects thus embody difference and discontinuity. Appadurai uses the term 'production knowledge' (1999: 42) to denote the point at which material, technical and culturally encoded understandings are most strongly anchored. In other words, when there is greatest clarity of intention attached to the object's creation. This knowledge is fractured as it moves to the point of consumption where a different form of knowledge, consumption knowledge, is produced. Inevitably, consumption knowledge is generated from, and subject to the technological, intellectual and cultural landscape into which it has been relocated and it differs from knowledge at the point of production. Accordingly, the distance travelled and the complexity of movement over time and space will exaggerate the discrepancies between production and consumption knowledge.

Linked to his insistence that context trumps all when it comes to the analysis of history, Appadurai (1996) values ephemerality, stating that incremental change is characteristic of the contingency of contemporary society. In his words, the 'inherent ephemerality of the present' and the 'aesthetic of ephemerality' is key to understanding contemporary cultural engagement (1996: 78). By ephemerality, Appadurai means that which moves through time as opposed to being of its time. He extends this argument to suggest that cultural practices that engage with ephemerality are now a 'serious form of work' that he defines as 'the social 
discipline of the imagination' (1996: 82). He rejects suggestions that the pleasure of consumerism and appropriation is the result of tensions between 'fantasy and utility' or 'individual desire and collective disciplines' (1996: 83). Instead, he proposes that it is the tensions between nostalgia and fantasy that produce pleasure, because 'the present is represented as if it were already the past'. From this perspective Appadurai asserts that ephemerality motivates many characteristics of contemporary practices, such as the increasing pace of the fashion cycle and the transitory nature of lifestyles on television and the mass media. Novelty, according to Appadurai, is merely a symptom of a new logic where 'desire is organized around the aesthetic of ephemerality' (1996: 84).

Appadurai's focus on the aesthetics of ephemerality is fundamental for understanding how the social imaginary operates in institutionalising fantasy. His contention that globalisation produces heterogeneity rather than homogeneity, in sum, is based on his insistence that context is the key factor to understanding how different cultures change the appropriation of globally distributed ideas and goods. Against this background, Appadurai stresses ephemerality as the condition and symptom of 'a new role for the imagination in social life' (1996: 31), where the imagination is framed as a social practice. This extends the proposal by Castoriades that the 'social imaginary' is 'instituted' in the bodies and structures established by each society. These structures develop from a culture's particular conception of social order, therefore they reflect the subjectivities of its dominant ideologies and history. Since the social imaginary also creates the structures which frame science and reason, so in Castoriades's terms, institutions are formed by significations that 'refer neither to reality nor to logic' (1997: 73).

For Castoriades, the social imaginary establishes institutions that add meaning to human experience (1997: 147). Here, Castoriades can be taken to mean that institutions are the embodiment of the social values inherent in a particular context. Yet, in his view, when institutions become overly specialised, they fragment human experience. One remedy he recommends for social fragmentation is interdisciplinarity (1997: 89). His rationale for this argument is the entwinement of two principles: 'society cannot exist without institutions' (1986: 95), while at the same time, 'society does not exist separately from those individuals of which it is comprised' (1997: 89-90). According to these principles, each individual is a 'walking fragment of the institution of society' (1986: 92). In other words, individuals are seen as contributing to the fantasies that combine to create the social imaginary. When specialisation fractures the social imaginary, interdisciplinarity can resuscitate the imaginative connections necessary for institutions to reflect social mores. From this, Appadurai surmises that the social imaginary, where imagination is seen as the cultural practice that shapes societies, is fundamental to understanding contemporary cultural trajectories as they occur in specific contexts. 


\section{An analysis of ICTV within the terms of the social imaginary}

As an experimental work situated in a museum, we see ICTV as engaged with the precepts of the social imaginary described by Appadurai and Castoriades. The work prompted audiences to question the veracity of museum exhibitions of objects presented with educational wall texts that purport to explain their meaning and value. The authoritative flavour of museum labels (listing their material, chronological and geographical characteristics) presents artworks and designs as artefacts and dislocates them from their conceptual context. ICTV interrupted this empirical framing of objects as so much natural history by inscribing objects with family folklore. Imbued with personal associations, the booklet revealed that the narratives surrounding objects are embellished and distorted over time. The scraps of gossip recorded in the booklet foregrounded the selection of objects in museum settings as an act of imagination. Such processes, like memory, are always incomplete. The work thus alluded to the fragmented nature of current institutional practices.

Drawing from Castoriades, we see such fragmentation as a product of overspecialisation in institutions that separate human experiences. As he sees it, a remedy for increased fragmentation is interdisciplinarity. It is this aspect of ICTV and PTMY - the breaching of the disciplinary boundaries between design, craft and visual art, that operates as institutional critique in the contemporary context. Themes that run through the two installations are the representation of the partiality of historical records and the finding of connections between what were once discrete disciplines.

We contend that, unlike previous generations of institutional critique, these experimental works question the separation by institutions of creative practices according to historical definitions of disciplinarity and specialisation. They frame the fragmentary effect of specialisation in relation to issues of the migration of fugitive objects through time. According to Kular, Toran and Jones an aim of ICTV was to 'substantiate a relay among many expressive cultural forms' (2013: 97). The multi-authored bricolage of ICTV demonstrated the decontextualisation and recontextualisation of objects when museums display artefacts in somewhat arbitrary, albeit traditional, categories. Moreover it challenged the traditions of connoisseurship in museological distinctions between fake and real, fiction and history. The insertion of contextual folklore surrounding each object questioned the museum as a repository of facts. At the same time it inscribed the objects and films with the historical events of the twentieth century. This combination cast the viewer in the role of connecting the disparate elements of the work. The effort required to connect the objects, historical dates and narratives comprising ICTV is not inconsiderable and the installation, as presented, required the viewer to undertake that work.

ICTV diverged from other experimental designs engaged with museum practices by explicitly and intricately connecting the ephemeral status of creative production to the contingency of historical and political events. The 
density of the work may also be one explanation for the relative silence on the work in design or visual art discourse. We suggest that further than the reader's agency in Barthes's analysis of the death of the author, the work evoked the social imaginary explored by Appadurai and Castoriades. Moreover the curated collection or legacy of Monarch's family in its whodunnit of clues makes historical processes visible.

Like the white gloves featured in the tales of Monarch's grandfather Zalman, the exhibited objects were connected to the linking device of the figure of Monarch. From our perspective, Monarch was in fact a MacGuffin. Although presented as a narrative of Monarch's family legacy, ICTV focused the realities of a globalised society that, in its heterogeneity, defaults to increasing fragmentation and specialisation. The artists' attention to contingency is demonstrated in the timeline that mixed personal with political events that led to the Lövy Singh clan residing in the United Kingdom. According to the statement of practice, the ambition of the work was to 'draw out and round out [Monarch's] larger world' and find a strategy to connect it to 'our historical moment' (Hayward et al. 2013: 96). The installation provoked ideas of migration, colonisation, appropriation and assimilation in the juxtaposition of ceramic replicas amid museum collections of bequests from notable families and the state.

The migratory histories of many, if not all, families were reflected in the Judeo-Indian (Ashkenazi Jewish and Punjabi Sikh) name Lövy Singh and the explanation that the ephemeral objects were emblematic of 'the intense upheavals and expansions of the last century' (Kular et al. 2010: cover). In the context of mass migrations, the narrative of the Lövy Singh clan is evocative. In the context of civil unrest about multiculturalism, we see ICTV as amplifying the institutionalisation of the social imaginary that surrounds these events in museological practices of collecting. The work thus alluded to the processes of the migration of people, cultures and artefacts and the ephemeral condition such translocations manifest.

The social imaginary - where institutions cultivate and make concrete the stories societies tell - was reflected in Monarch's family archive of relics and interconnecting tales. In his description of the social imaginary, Castoriades notes that its meaning 'refers neither to reality, nor to logic' (1997: 186). An example of how the social imaginary operates in ICTV was exemplified in the caption for a farm scene constructed in Lego. Here Monarch confessed that his grandfather once told him a story that he was forbidden to repeat (Kular et al. 2010: 9). Instead, he constructed the tale in Lego bricks, reconfiguring the scene in various arrangements as he tried to understand the complicated world of adults. The claim that Monarch stored the Lego in the attic on the evening of his grandfather's death, left the museum visitor to construct their own narrative about the family secret. From our perspective, the anecdote playfully repositions the museum as society's attic. Rather than see this as a criticism, the Lego farm is a symbol of the museum as the institutionalisation of society's fantasies, its social imaginary. We see the opening up of museological 
categories and practices by contemporary interdisciplinary practitioners (in this case intermingling art and design in experimental design) in counter-histories, such as ICTV, as an interruption to further social fragmentation.

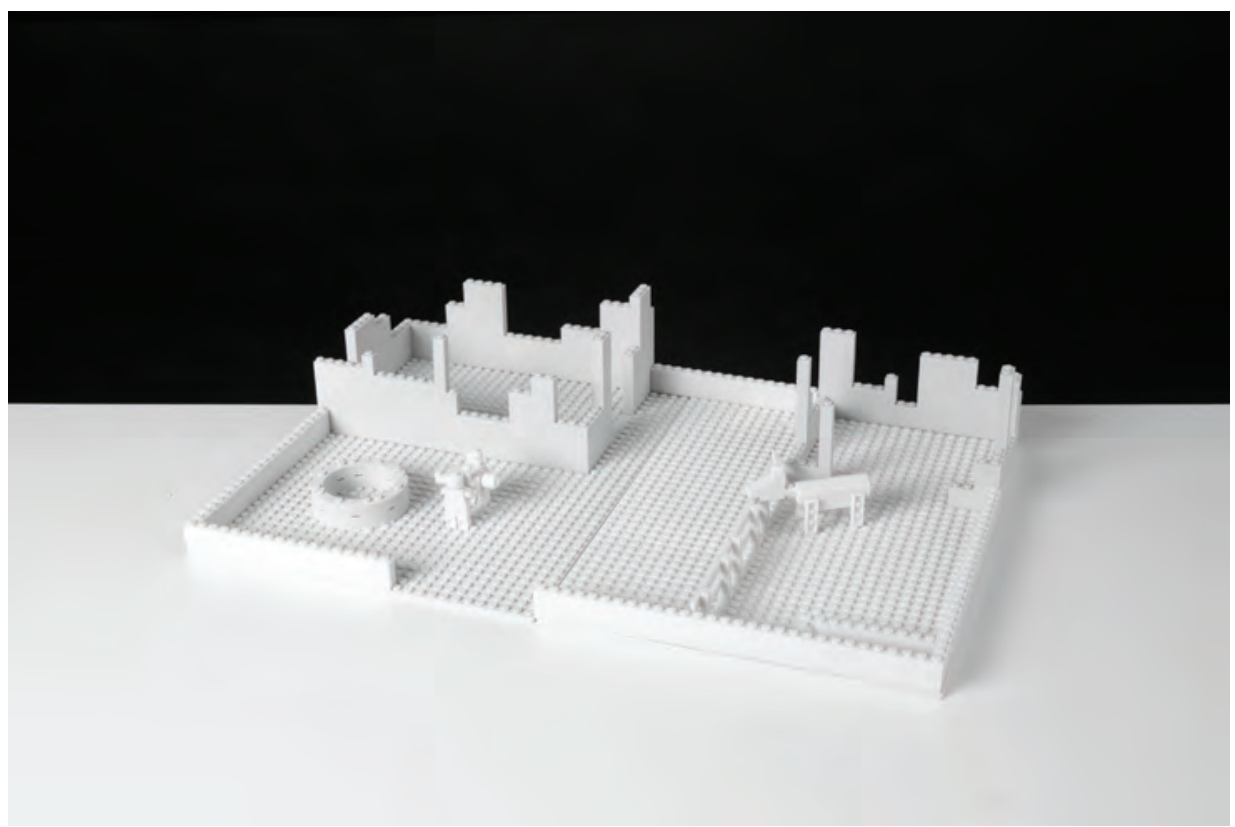

Figure 5. Onkar Kular, Noam Toran and Keith Jones, Lego farm, 2010

Photo: Diego Trujillo

In sum, ICTV recombined issues of interdisciplinarity, the effects of globalisation and recast the museum as an assemblage of fugitive objects that symbolise the social imaginary. The chief apparatus with which it layered this narrative, we suggest, is Monarch, the heir to the family legacy. When seen as a MacGuffin, the focus shifts to the social imaginary of global history and how it may be defragmented. As Auger notes, design fictions and experimental design explore 'complex human desires or fears' (2013: 10). In the migratory culture of globalisation, ICTV prompted viewers to rethink the plight of populations seeking to escape civil unrest. The multicultural bricolage of most urban metropolises is no longer seen as cosmopolitan, but instead, divided. The two principles of the social imaginary proposed by Castoriades illuminate ICTV: 'society cannot exist without institutions' (1986: 95), and that 'society does not exist separately from those individuals of which it is comprised' (1997: 89-90). His claim that each individual is a 'walking fragment of the institution of society' (1986: 92) is exemplified in ICTV, particularly when the artists state that ICTV ' $\ldots$ is less an effort at resolving these tensions or contradictions than a restaging of them' (2010: 99). Here they implicitly refer to dichotomies, such as pure and impure, insiders and outsiders. 


\section{An analysis of $P T M Y$ in relation to social imaginary}

A curatorial project by an artist conversant with the practices of crafts production, PTMY was constructed around aesthetic markers that may be considered central to the craft tradition. These included the concrete indicators of material and form, as well as more nuanced aspects of process, colour and surface; in other words, a language of aestheticisation. We see this project as moving beyond mere aestheticisation, however, to provoke questions about ascriptions of legitimacy in the construction of historical knowledge and the authority of institutions in the validation and circulation of practices designated as art, design and craft. In this sense, PTMY underscored the differences between consumption and production knowledge noted by Appadurai. It drew attention to the presumed locus of knowledge in an organisation such as the MOA and the role of the curator, as well as audience understandings of the curated museum experience. That is, the fragmentation of experience exemplified by the highly specialised institution.

The assumptions that accompany audience expectations were captured in a review of PTMY. Here, Laurence (2012) spoke of the exhibition's 'marvellous sensibility' and claimed she was 'captivated' by 'new sets of visual dynamics [that] emerge'. Yet ultimately, Laurence saw such dynamism as 'troubling' because the exhibition was 'different ... from what we expect of an anthropology museum', lacking the pedagogical markers of case labels and wall text to guide the audience in interpretation. In Appadurai's terms, Laurence is looking for insights on the production knowledge associated with each object, the preserve of the professional curator, to be elucidated via the lens of contemporary scholarship and distributed in explanatory data, such as exhibition notes. Appadurai's insistence that consumption knowledge is distinct and disarticulated from production knowledge, and his emphasis on context, opens up and legitimises the form of knowledge that is generated at the point of consumption: that is by the viewer engaged in the act of viewing the exhibition.

In the socially constructed landscape of the contemporary museum, therefore, the PTMY audience is construed as expert in its interpretation. ICTV used the device of an exhibition booklet to hint at the unreliability of a family history it had constructed, thereby underscoring the fragmentary nature of the museum and its practices. For PTMY, the absence of labels was employed to similar effect, alerting visitors as constituents of the social imaginary to the nature of their individual agency in producing meaning and to its difference from externally generated information, the product of institutional specialisation. Like the viewer unravelling clues in ICTV, the PTMY visitor is invited to make meaning from attending to the fine detail of objects that comprise each tableau.

On reflection, Hanssen Pigott's process in gathering culturally disparate, unnamed objects around an aesthetic sensibility may be read against colonising practices of collection, including those of contemporary 'styling', the province of design for marketing and the tendency that Marxist commentator 
Wolfgang Fritz Haug describes as rendering the fields of culture and marketing 'indistinguishable' (2000: 41). Laurence (2012) described viewers as 'seduced' by the 'visual delight' of Hanssen Pigott's arrangements, but the intent and effect of these interventions are the antithesis of the rapacious collector. In PTMY, Hanssen Pigott arranged artefacts of diverse geographic and temporal origin such that each had the effect of highlighting the presence and particularities of another. The delicacy of a white Korean garment, for example, called attention to the faded passages of white slip that define the features of a Chinese clay figure directly below. By definition, a museum of anthropology represents a vast, centralised depository of globally sourced artefacts and its archive typifies the saturation of information and objects associated with globalisation. But at the point of viewing PTMY tableaux, Appadurai's contention that such a deluge manifests heterogeneity - awareness of the particular and the local - is brought into play.

Museum publications identified Hanssen Pigott as a guest invited to select, arrange and configure MOA artefacts (MOA 2012). Defined as a practising visual artist, she is a visitor to the museum, separate from specialist museum professionals who administered the project, and, in that sense, part of the general audience group. In other words, a representative of museum visitors. By inserting her own works among the arrangements in several cabinets, Hanssen Pigott restated her presence and the authority of her process, a form of selection described by MOA curator Caroll Mayer as originating from 'different sensibilities ... and sense of aesthetic' (2013). The PTMY installation removed artefacts from their museological designation and reframed them in relationships that were intended to trigger references shared by the audience of which Hanssen Pigott was construed as part. Cort (2013) pointed to the enactment of this strategy in the development of the earlier work Remembrance at the Freer Gallery, a response to discussion of the Vietnam War as it has entered the collective community memory. Hanssen Pigott was placed as both agent and archetype of the audience, sharing cultural memories and the sensibility upon which her references were based. In Castoriades terms, 'a walking fragment of the institution of society' (1986: 154).

At the MOA, Mayer described aesthetic and poetic devices such as 'translucency' and 'materiality' around which the groupings were aggregated (2013). In this location, the elimination of both titles and case notes gave the visitor no recourse to externally generated documentation explaining the premises of their selection, so that interpretive readings of the works were separated from curatorial expertise. Hanssen Pigott's identification with the audience bridged the fragmentation that Castoriades associates with specialisation, to restore viewer connections with the cultural practice of the social imaginary. PTMY places the museum and its disparate collection of objects within the frame of the social imaginary, alerting us to the mechanisms with which individuals both constitute and are constituted by the institution of society. 


\section{Conclusion and implications}

Several characteristics distinguish the installations and interventions of ICTV and $P T M Y$, including their background specialisations, their materiality, context and process. Yet both works question assumptions upon which the museum exhibition is conventionally assembled, around disciplinary specialisation. Each work contests the definition of objects in serving the didactic claims of singular, authoritative constructions of cultures, geographies and technologies. In so doing, they raise provocative questions about globalisation and demonstrate more fluid strategies with which to reflect on the tensions between history and memory, the institution and the individual.

While both installations explore the social imaginary created by the institutional practices of museums, they engage differently with Appadurai's observations of production and consumption knowledge. In ceramic prototyping, ICTV manufactured a simultaneous moment of production and consumption. By this we mean Kular, Toran and Jones produced ephemeral or ghostly objects consumed as invented artefacts from family narratives. The ICTV artists thus manufactured stories to create a span of time in a fake history that evoked significant issues in current events concerning migration. From our perspective ICTV engaged with and extended how the social imaginary, described by Castoriades and Appadurai, operates. That is, ICTV manifested the attic-like appeal of museums, such as the V\&A, and allowed viewers to entertain the fantasies and family narratives that such collections can evoke.

As with the ICTV artists, Hanssen Pigott recombined objects to construct tableaux that conjured poetic and narrative associations of her own invention. She stripped away labelling devices that contributed to the interpretation of each artefact in its conventional museum setting. PTMY combined objects from different historical periods, but was unconcerned with their 'real' histories and relative antiquity. Accordingly, the work deactivated the centrality of time between production and consumption as the key to understanding the recombinations around which each tableau within PTMY was constructed. The interpretation of the artefacts relied on the engaged, imaginative work of viewers constructing meaning from the past in the present, at the point of 'consumption', independent of the logic of the museum.

PTMY underplayed the point of production and its associated knowledge as a factor in interpreting works; it compressed time and relied on an exercise of the imagination to construct meaning. Nonetheless, Laurence's (2012) critique of the exhibition refers to the disjunction between curatorial purpose assumed of the anthropological museum by its regular visitors, and the less familiar approach employed by Hanssen Pigott. The 'unsettling' (Laurence 2012) recalibration of expectation and interaction demanded by PTMY produced an unintended effect in highlighting the disjunction between production and consumption knowledge 
in different contexts over time, and the institutional determination of the museum in mediating knowledge. Despite these differences, both works re-imagined history via partial memories and, thereby, re-imagined alternative futures.

Further, both installations evoked the idea of social groups and the changes to specialised knowledge that is required when interdisciplinarity is revalued. In the case of ICTV, notions of family and the layers of cultural background of which we are all made, featured as reflective of a history that is, at best, partial, fragmentary and always contingent. In PTMY, markers of human community were structured as a reflective narrative in the performative space of museum display. We suggest the two works discussed here thus provide models for rethinking the past and the present within the terms of interdisciplinarity suggested by Castoriades. Whether or not history is irrelevant, as some descriptions of design infer (Julier \& Narotzky 1998), or inescapable, as definitions of craft as a truth to tradition suggest (Yanagi 1972), interrupting the historical record, as exemplified in these interdisciplinary works, contextualises institutional critique in a wider defragmented definition of creative practice than has been seen for some time. That is, the artworks encompass aspects of design, craft and visual art. Our analysis is that, as such, they evoke Appadurai's and Castoriades's thesis of the social imaginary: it is people who make institutions and history. Further, the artistic approaches of Kular, Toran, Jones and Hanssen Piggot blended with curating and drew out the distinction between the production knowledge and consumption knowledge of objects, and the need to understand context. Concurring with Appadurai, we see context as the critical factor in the interpretation of such projects.

In conclusion we contend that, when seen within the social imaginary, where institutional practices are said to reflect the fantasies of society, the experimental approach to curatorial and exhibition norms in the two installations model timely alternatives. ICTV presented new work with contemporary rapid prototyping technology, albeit in ceramic, a material associated with ancient civilisations. That is, it referenced the collection of the V\&A without reproducing it. PTMY drew from a repository of artworks and archeological objects separated at their origin by time, geography and material, and assembled them in a manner that implied the conventions of museology. In both works, the invented arrangements invited viewers to attend to subjective responses as authoritative readings of museum display. In this they pointed to how the currents of heterogeneity in contemporary globalisation demand richer understandings of interdisciplinarity informed by the social imaginary.

Dr Katherine Moline is a visual artist and design researcher. As a senior lecturer she is the Program Coordinator: Masters by Research (Art, Design, Media, Art History) at the College of Fine Arts, University of New South Wales. Her current research focuses on the convergences and differences between experimental practices in design and visual art.

Jacqueline Clayton. As visual artist, ceramic designer and design researcher, Clayton's work spans disciplines and definitions of practice. 
Over the last two decades she has engaged questions on the role of objects in definitions of place and self, producing a range of installationbased responses that have been exhibited in Australia and overseas.

\section{References}

Adamson, G. 2013, The Invention of Craft, London: Bloomsbury.

Ambasz, E. (ed.) 1972, Italy: the New Domestic Landscape, New York: Museum of Modern Art.

Appadurai, A. 1996, Modernity at Large, Cultural Dimensions of Globalisation, Minneapolis: University of Minnesota Press.

- - 1999, The Social Life of Things, Gateshead: Cambridge University Press.

Augé, M., Young, J.E. and De Jager, M. 2004. Oblivion, Minneapolis: University of Minnesota Press.

Auger, J. 2013, 'Speculative design: Crafting the speculation', Digital Creativity, viewed 3 May 2013, http://dx.doi.org/10.1080/14626268.2013.767276.

Barthes, R. 1977, Image, Music, Text, New York: Hill and Wang.

Blauvelt, A. 2003, 'Strangely familiar: Design and everyday life', in A. Blauvelt (ed.), Strangely Familiar: Design and Everyday Life, Minneapolis: Walker Art Center, pp. 14-37.

Bleeker, J. 2009, Design Fiction: A Short Essay on Design, Science, Fact and Fiction, Manchester: Near Future Laboratory.

Castoriades, C. 1986, 'First institution of society and second-order institutions', in C. Castoriades, Figures of the Thinkable, Palo Alto: Stanford University Press, pp. 91-104.

- - , 1997, 'Imaginary and imagination at the crossroads', in Castoriades, Figures, pp. 71-90.

Clayton, J. 2010, Another Silk Road, Sydney: Ivan Dougherty Gallery.

Coles, A. 2005, DesignArt, London: Tate.

Conner, S. 2012, 'Art meets artefact at MOA', Vancouver Sun, 1 November, viewed 6 April 2014, http://www2.canada.com/vancouversun/news/archives/ story.html?id=4b7559c3-6d67-41be-83d2-0d664c8cf77a.

Cort, L. 2013, personal communication, 19 June.

Dunne, A. 1999, Hertzian Tales, London: Royal College of Art. 
Dunne, A. \& Raby, F. 2013, Speculative Everything: Design Fiction and Social Dreaming, Cambridge MAS: MIT Press.

Guixé, M. 2007, 'Museum Guixé', in K. Garcia-Antón, E. King \& C. Brändle (eds), Wouldn't it be Nice: ... Wishful Thinking in Art and Design, Centre d'Art Contemporain Genève.

Hanssen Pigott, G. 2004, 'The rightness of form', Ceramic Review, vol. 207, May/June, p. 25.

Haq, N. 2010, 'Laissez-faire heterotopia', in Things Uncommon: Noam Toran, Paris: Le Lieu du Design, pp. 8-9.

Haug, W.F. 2005, 'Commodity aesthetics revisited: Commodity aesthetics as a motor of globalisation', in New Elements of a Theory of Commodity Aesthetics, pp. 37-51, viewed 3 May 2011, www.wolfgangfritzhaug.inkrit.de/ documents/NewElementsCommodityAesthetics.pdf.

Hayward, S., Jones, K., Toran, N. \& Kular O. 2013, 'I cling to virtue: An exhibition review and statement of practice', Design and Culture, vol. 5, no. 1, pp. 89-102.

Hein, H.S. 2000, The Museum in Transition: A Philosophical Perspective, Washington, D.C.: Smithsonian Institution Press.

Julier, G. 2008, The Culture of Design, London: Sage Publications.

Julier, G. \& Narotzky V. 1998, 'The redundancy of design history', conference paper, Practically Speaking Conference, Wolverhampton University, United Kingdom, viewed 19 June 2009. http://www.leedsmet.ac.uk/as/ artdesresearch/Projects/design_observatory/the_redundancy_of_design_ history.htm.Kular, O. \& Toran, N. in collaboration with Jones, K.R. 2010, I Cling to Virtue, London: Victoria and Albert Museum.

- - 2011, I Cling to Virtue, London: Dent-De-Leone.

Laurence, R. 2012, 'Pleased to meet you at the Museum of Anthropology is both captivating and unsettling', Straight.com, 6 November, viewed 25 March 2013, http://www.straight.com/arts/pleased-to-meet-you-museumanthropology.

Mayer, C. 2013, personal communication, 4 July.

MOA 2013, Pleased to meet you: Gwyn Hanssen Pigott, blog, viewed 15 May 2013,http://www.moa.ubc.ca/blog/?p=3895.

- - 2012, Pleased to meet you: Gwyn Hanssen Pigott, exhibition statement, viewed 15 May 2013, http://moa.ubc.ca/experience/exhibit_archived_ details. php?id=965. 
Moline, K. 2007, Connections: Experimental Design, Sydney: Ivan Dougherty Gallery.

- - 2012. 'The legacy of historical design collectives in contemporary experimental design: A case-study of global tools and digestion by Matali Crasset', in H. Edquist \& L. Vaughan, The Design Collective: An Approach to Practice, Newcastle upon Tyne: Cambridge Scholars Publishing.

Nora, P. 1989, 'Between memory and history: Les Lieux de Mémoire', Representations, vol. 26 (Spring), pp. 7-24.

O'Neill, P. 2012, The Culture of Curating and the Curating of Culture(s), Cambridge MA: MIT Press.

Perry, G. 2011, Grayson Perry and the Tomb of the Unknown Craftsman, London: British Museum Press.

Poynor, R. 2003, No More Rules: Graphic Design and Postmodernism, London: Laurence King Publishing.

Rock, M. \& Sellers, S. 1998, 'The museum of the ordinary', Eye: International Review of Graphic Design, vol. 7, no. 28, pp. 32-35.

Tannert, C. \& Tischler, U. (eds) 2004, Men in Black, Berlin: Künstlerhaus Betanien.

Wells, K. 2011, 'Gwyn Hanssen Pigott, pottery and presence', Craft Australia, viewed 3 March 2013, http://www.craftaustralia.org.au/library/interview. php?id=gwyn-hanssen-pigott-pottery-and-presence.

Williams, G. 2009, Telling Tales: Fantasy and Fear in Contemporary Design, London: V\&A Publications.

Woodham, J. 1997, Twentieth Century Design, Oxford University Press.

Yanagi, S. 1972, The Unknown Craftsman, Tokyo; Palo Alto CA: Kodansha International. 
This text taken from craft + design enquiry issue 6, 2014, Craft.Material. Memory, Edited by Anne Brennan and Patsy Hely, published 2014 by ANU Press, The Australian National University,

Canberra, Australia. 